Don Quixote in the spanish litterature according to Dámaso Alonso

\title{
El Quijote en la literatura española según Dámaso Alonso
}

Manuel Piqueras Flores

Universidad Autónoma de Madrid manuel.piqueras@uam.es

DOI: http://dx.doi.org/10.15366/bp2018.18.018

Bajo Palabra. II Época. No18. Pgs: 355-372

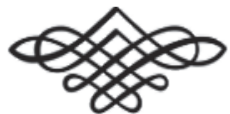


Este trabajo se ha llevado a cabo gracias a la financiación del Programa de Ayudas para la Formación del Personal Investigador de la Universidad Autónoma de Madrid.

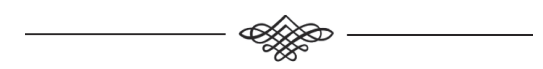

Recibido: 11/06/2017

Aprobado: 29/07/2018

\section{Resumen}

El presente trabajo estudia los textos que Dámaso Alonso dedicó al Quijote. Se profundiza en dos aspectos fundamentales: el papel de la novela de Cervantes dentro de la historia de la literatura española y el acercamiento de Alonso a la obra desde los tres niveles que se pueden abordar un texto literario según sus planteamientos teóricos: la lectura habitual, la crítica y la Estilística o Ciencia de la Literatura.

Palabras clave: Quijote, Dámaso Alonso, Estilística, Realismo español.

\section{Abstract}

This paper analyzes the texts that Dámaso Alonso wrote about Don Quixote. We deepen in two fundamental points: the role of the Cervantes' novel in the spanish litterature history and the approach of Alonso to the work from the three differents levels according to his own theorical framework: the habitual reading, the critical Reading and the Stylistic or Literary Science.

Keywords: Don Quixote, Dámaso Alonso, Stylistic, Spanish realism. 
Oon el estallido de la Guerra Civil española en 1936, varios de los miembros más destacados de la joven Escuela Filológica Española — surgida bajo el magisterio directo o indirecto de don Ramón Menéndez Pidal - se vieron obligados a seguir su carrera académica fuera de nuestras fronteras. Como bien explica José Montero Reguera ${ }^{1}$, muchos de los filólogos que abandonaron España eran eminentes cervantistas -entre ellos, Américo Castro, que con El pensamiento de Cervantes (1925) había marcado uno de los hitos fundacionales del cervantismo moderno-, mientras que entre aquellos que se quedaron existen pocos casos de estudiosos dedicados con asiduidad a investigar la literatura de Cervantes.

Para Montero Reguera, precisamente el hecho de que "los filólogos del Centro de Estudios Históricos en Espańa no se ocuparon con frecuencia del Quijote" ${ }^{2}$ tiene que ver con la importancia de las ideas de Castro:

Quizás también el extraordinario influjo de las ideas de Castro sobre todos sus discípulos, tanto en Estados Unidos como en Espańa: pero aquellas no eran del todo bien vistas en España, con una situación política que quiso hacer de Cervantes un héroe glorioso con una imagen afín al régimen, muy alejada de la que Castro nos ofreció. ${ }^{3}$

No obstante, el propio Montero Reguera admite que los trabajos sobre el Quijote de los filólogos que permanecieron en España «ofrecen páginas de enorme interés» ${ }^{4}$. Como ejemplo, cita a Rafael Lapesa y a Manuel de Montoliú, pero también a Enrique Moreno Báez y a Dámaso Alonso. El caso de Moreno Báez resulta interesante porque en sus Reflexiones del Quijote discrepa abiertamente con Castro, especialmente en lo que concierne a la cuestión religiosa en los textos cervantinos 5 . También Dámaso Alonso admite sus diferencias con Castro, no específicamente en cuanto a Cervantes y al Quijote, pero sí en cuanto a la "interpretación de la

\footnotetext{
${ }^{1}$ Montero Reguera, J., El "Quijote" durante cuatro siglos. Lecturas y lectores, Valladolid, Universidad de Valladolid, p. 96.

2 Ibid., p. 97.

3 Idem.

4 Ibid., p. 96.

5 Moreno BÁez, E., Reflexiones sobre el "Quijote”, Madrid, Editorial Prensa Española, pp. 47-60. No solo Moreno Báez, sino otros muchos discreparon con don Américo en este sentido, fuera de España — por ejemplo, Paul Descouzis en su Cervantes a nueva luz-, pero también dentro de ella. Particularmente importante resulta el Cervantes, creador de la novela corta española de Agustín González de Amezúa, publicado en el año 1956, que, si bien se ocupa sobre todo de las Novelas ejemplares, tangencialmente establece conclusiones sobre el Quijote, que se oponen casi frontalmente a las de Castro.
} 
vida española" desde un punto de vista total ${ }^{6}$, marco en el que precisamente se insertan los trabajos cervantinos de don Américo, no solamente El pensamiento de Cervantes, sino también Hacia Cervantes (1958) y Cervantes y los casticismos españoles (1966).

Más allá del peso de los trabajos críticos de don Américo, Pablo Jauralde plantea dos explicaciones posibles a la ausencia de un verdadero cervantismo español en gran parte del siglo XX: por un lado, la dificultad del lector español para distanciarse de su modo de concebir la novela de Cervantes ${ }^{7}$, lo que Fernando Rodríguez Mansilla ha llamado una explicación "de índole metafísica"; por otro, el método de estudio aplicado a los textos, la Estilística (entre cuyos resultados destaca "los estudios [...] de Amado Alonso y Dámaso Alonso" "), que imposibilitaba para Jauralde "captar aquellos elementos que no se resolvían bonitamente en palabras y oraciones" ${ }^{10}$ : Para el crítico, la generación de Amado Alonso, Dámaso Alonso y Rafael Lapesa era consciente de la limitación de su método:

Los viejos maestros lo sabían —en realidad siempre supieron cuál era su tarea y dónde estaba el límite de sus trabajos-, y, pudorosamente, dejaron el campo de la crítica cervantina libre y siguieron enriqueciendo con su sabiduría filológica el tesoro de los textos bien editados, el estilo, la historia de la lengua... ${ }^{11}$

Y esta situación es la que explicaría precisamente la ausencia de textos críticos sobre Cervantes:

Solo rebuscando mucho se encuentra uno con apuntes filológicos de Lapesa, con algún escarceo mínimo de Dámaso Alonso, con la agudeza filológica de Amado Alonso, con la sabiduría cervantina de Alonso al fondo de toda su obra crítica y creadora. Cervantes, en todos estos casos, ocupa el fondo de la escena. Ninguno de ellos se ha asomado jamás, en profundidad, a Cervantes, cuya obra conocen soberanamente, doy fe de ello. ${ }^{12}$

Tanto Jauralde como Montero Reguera señalan la ausencia de lecturas críticas del Quijote hechas desde el mundo de la filología, pero hay que recordar que durante la posguerra española salen a la luz textos sobre la novela cervantina también desde otros ámbitos. Jauralde, por ejemplo, cita a Torrente Ballester y a Francisco Ayala

\footnotetext{
${ }^{6}$ Así lo explica en una entrevista para Televisión Española: Soler Serrano, J., "Entrevista a Dámaso Alonso”, min. 16:55-17:05.

7 Jauralde, P., "Cervantes y la escuela filológica española”, en Voz y letra, vol. 16, p. 7

8 Rodríguez Mansilla, F., "Dámaso Alonso lee el Quijote: nación, realismo e intrahistoria en el cervantismo español”, en eHumanista, vol. 9, p. 175.

9 Jauralde, P., op. cit., p. 4.

10 Ibid., p. 7.

11 Ibid., p. 7.

12 Ibid., p. 5.
} 
(este último, por cierto, en el exilio) ${ }^{13}$. El caso de Dámaso Alonso, como el de otros miembros de la generación del 27, es singular, porque su dedicación a la literatura se dio desde dos puntos de vista diferentes: la del creador (más concretamente, la del poeta) y la del estudioso. Como poeta, Dámaso Alonso se convierte junto con Vicente Aleixandre en uno de los grandes referentes de las jóvenes generaciones tras la guerra civil. Como filólogo, en 1941 obtiene la cátedra de Filología Románica en la Universidad Central, vacante desde que Menéndez Pidal la dejara. Además, en 1948 ingresa en la Real Academia Española, de la que con posterioridad llega a ser director, sustituyendo en este cargo también a Menéndez Pidal ${ }^{14}$.

En este sentido, los trabajos sobre el Quijote parecen sin duda escritos por el Dámaso Alonso filólogo, y no por el Dámaso Alonso poeta ${ }^{15}$. En general, los distintos textos sobre Cervantes conforman los nueve apartados de La novela cervantina, opúsculo publicado en dos ocasiones, en 1950 y 1969; todos excepto "El hidalgo Camilote y el hidalgo don Quijote" y "Maraña de hilos", dos artículos sobre posibles fuentes del Quijote y Los baños de Argel respectivamente. Como decíamos, estos trabajos pertenecen al ámbito de la filología tanto por su objeto de estudio como por su afán de rigurosidad. Sin embargo, pueden encontrarse algunas afirmaciones del propio Alonso en la introducción de La novela cervantina que en principio matizan esta categorización:

Quiero sencillamente traer ante ustedes mis reacciones personales frente a la novela cervantina. He dicho mis reacciones personales, y debo en seguida rectificar. Mis reacciones se han producido dentro de una tradición y dentro de una evolución general del la Humanidad culta. Las llamo "personales" porque dentro de esa gran tradición yo soy un lector más, una sensibilidad puesta enfrente de esa gran vibración, de ese gran destello que es la obra cervantina. ${ }^{16}$

Las palabras de Dámaso Alonso cobran un significado especial si las leemos a la luz de su marco teórico. En Poesía española. Ensayo de métodos y límites estilísticos, seguramente su trabajo crítico más importante (del que Jauralde, para expresar el predominio de la Estilística, dice que "se leía como un delicioso evangelio

\footnotetext{
13 Ibid., p. 3.

${ }^{14} \mathrm{http} / /$ www.rae.es/la-institucion/los-academicos/directores.

15 Cabe precisar que muchos de los trabajos críticos de nuestro autor fueron publicados con ligeros retoques y con títulos diferentes en lugares distintos, especialmente en lo que concierne a sus trabajos cervantinos. El caso mejor explica esta situación es su articulito sobre el proceso de engaño y desengaño de Sancho Panza, publicado hasta cinco veces de forma autónoma antes de la muerte de Alonso en 1950, 1968, 1984 y 1989, además de ser traducido al alemán en 1968. Además, el texto se introdujo como apartado en La novela cervantina (1969). Para un panorama completo de esta situación bibliográfica, puede verse Jaime Fernández, Bibliografía del "Quijote" por unidades narrativas y materiales de la novela, Alcalá de Henares, Centro de Estudios Cervantinos, pp. 57-58.

16 Alonso, D., La novela cervantina, en Obras completas, vol. 8, Madrid, Gredos, p. 587.
} 
crítico" ${ }^{17}$ ), Alonso distingue entre dos posibles conocimientos de la literatura (y, en especial, de la poesía): el del lector habitual y el del crítico:

Dos son los conocimientos normales de la materia literaria [...]. El primer conocimiento de la obra poética es, pues, el del lector, y consiste en una intuición totalizadora [...]. Pero hay un segundo grado de conocimiento poético. Existe un ser en el que las cualidades del lector están como exacerbadas [...]. Ese otro ser excepcional, el crítico, no sólo tiene una poderosa intensidad de expresión, sino que reacciona, en general, ante todas las intuiciones creativas. ${ }^{18}$

La propuesta de su estudio consiste precisamente en proponer un tercer tipo de conocimiento literario, el de la Estilística o, término que él prefiere, el de la Ciencia de la Literatura, una disciplina en ciernes:

Fui primero, pues, lector entusiasta; y luego me aupé -con juvenil osadía- a crítico [...]. Como en otra parte de este libro se explica, había pasado por el primer conocimiento poético y por el segundo, y estaba empeńado en los caminos del tercero: de un conocimiento del poema (de este y de aquel poema) como problema, como objeto de indagación científica, puente a su vez por el que se podría llegar al planteamiento del problema total de la poesía. ${ }^{19}$

Resulta llamativo que uno de los filólogos más importantes de la España del siglo $\mathrm{XX}$, aquel que propone la creación de un tercer escalón en el conocimiento literario $^{20}$ por encima del conocimiento del lector y del conocimiento del crítico, al reflexionar sobre el Quijote, la joya de nuestra literatura, lo haga desde sus "reacciones personales", como "un lector más" dentro de "una gran tradición" ${ }^{21}$. Al presentar $L a$ novela cervantina como el resultado de una lectura más del Quijote, Dámaso Alonso se sitúa en el primer escalón del conocimiento literario tal como él lo entiende. Tres son los objetivos que el autor se propone al inicio de La novela cervantina:

¿Se puede aún hablar de realismo? ¿Se puede hablar aún de "literatura española"? ¿Se puede aún hablar de Cervantes en una esfera de normalidad crítica, es decir, sin pretender ver en él lo que nunca habían visto millones de lectores durante tres siglos y medio? Sí, todo eso intento: hablar, una vez más, del realismo de la literatura espańola, hablar de Cervantes sin tratar de colarles a ustedes algún descubrimiento sensacional. ${ }^{22}$

Nos interesa ahora, sobre todo, el tercer punto: la normalidad crítica a la hora de abordar la obra cervantina. Estas palabras constituyen una crítica contra las

\footnotetext{
17 Jarualde, P., op. cit., p. 6.

18 Alonso, D., Poesía española: ensayo de métodos y límites estilísticos, Madrid, Gredos, pp. 37, 38, 203.

19 Ibid., p. 9.

20 Ibid., p. 403.

${ }^{21}$ Alonso, D., La novela cervantina, p. 587.

22 Ídem.
} 
sobreinterpretaciones que, desde diversos ámbitos, se habían hecho del Quijote. En Poesía española, precisamente al explicar la importancia del lector habitual, Alonso hace uso de la ironía para censurar comportamientos críticos, usando como ejemplo el Quijote:

Las obras literarias han sido escritas para un ser tierno, inocentísimo y profundamente interesante: "el lector". Ni el Quijote se creó para los cervantistas (aunque haya algún cervantista que piense de otro modo), ni el teatro de Shakespeare para la filología alemana. ${ }^{23}$

Si La novela cervantina se presenta, sobre todo, como un conjunto de reflexiones a partir de una lectura personal de la obra de Cervantes (no solamente del Quijote sino también de algunas de las Novelas ejemplares), podemos entender entonces que Dámaso Alonso optara por no incluir, como un apartado más, "El hidalgo Camilote y el hidalgo don Quijote", uno de sus primero estudios sobre el Quijote. Este pequeño artículo indaga en la relación entre Camilote, personaje ridículo del Primaleón (libro de caballerías que Alonso conocía muy bien), y don Quijote. En efecto, empezando por lo parecido del nombre, las coincidencias son muchas: hasta siete consigue exponer el estudioso en una clara explicación ${ }^{24}$. En general, cuando el cervantismo posterior se ha referido a este trabajo, no lo ha hecho para refutarlo, sino para considerarlo una importante aportación. En Cervantes y su concepto del arte. Helena Percas comenta brevemente el artículo de nuestro autor:

En "El hidalgo Camilote y el hidalgo don Quijote" de su libro Del Siglo de Oro a este siglo de siglas (Madrid, 1962), establece Dámaso Alonso los puntos de contacto entre el Primaleón y el Quijote (págs. 20-28), así como las divergencias: Camilote acaba siendo un caballero en serio, vencedor de varios otros (pág. 23), mientras que Cervantes desarrolla el aspecto cómico, igual que Gil Vicente en El Don Duardos, inspirado, igualmente, en la misma historia de Camilote y Maimonda. ${ }^{25}$

También Giuseppe Grilli, al estudiar las reescrituras cervantinas de los libros de caballerías recuerda a Alonso:

Es sabido cómo Dámaso Alonso quiso leer en la investidura de Camilote una premisa o antecedente de la ironía cervantina. Y efectivamente las semejanzas entra ambas burlas son

${ }^{23}$ Alonso, D., Poesía española, p. 37.

${ }^{24}$ Alonso, D., "El hidalgo Camilote y el hidalgo Don Quijote", en Del Siglo de Oro a este siglo de siglas, Madrid, Gredos, p. 22.

25 Percas, H., Cervantes y su concepto de arte: estudio crítico de algunos aspectos y episodios del "Quijote", Madrid, Gredos, p. 29. 
evidentes, aunque el episodio del Primaleón más parece acordarse con cierto espíritu de la Segunda parte. ${ }^{26}$

Hay ocasiones en las que el cervantismo no cita siquiera Alonso, al hablar de la identificación entre don Quijote y Camilote, lo que supone una prueba de la aceptación de su contribución. Así, en su edición del Quijote, Florencio Sevilla y Antonio Rey explican simplemente:

El nombre, desde luego, extrema de todo punto la burla, pues, sobre denotar 'la pieza del arnés que cubría el muslo del caballo' (Tesoro), incorpora el sufijo -ote, con sus connotaciones ridiculizadoras, que alcanza cotas de parodia literaria y caballeresca cuando se asocian con Lanzarote [...] o con Camilote (el ridículo hidalgo, enamorado de la feísima Maimonda, en el Primaleón y Polendos [1516] y en Don Duardos [1522], de Gil Vicente. ${ }^{27}$

En cuanto a si Cervantes tomó como modelo el personaje original de Camilote, del Primaleón, o su recreación de la Tragicomedia de Don Duardos, Dámaso Alonso se inclina por la primera opción, aunque puntualiza que "lo verosímil, lo humanamente pensable es que conociera lo mismo el Primaleón que la Tragicomedia de Don Duardos" 28 .

Como vemos, aunque en su propuesta de creación de una Ciencia de la Literatura Dámaso Alonso defiende una investigación ahistórica ${ }^{29}$, este concepto "no le impide rastrear como pocos las fuentes de nuestra literatura" ${ }^{30}$, por decirlo con palabras de José Portolés. Por ello, como decíamos, dentro de los tres grados de conocimiento literario que Alonso distingue teóricamente, "El hidalgo Camilote y el hidalgo don Quijote" se situaría en el segundo grado, el del territorio del lector crítico. La naturaleza de este artículo, por lo tanto, sería en principio distinta a la de La novela cervantina.

No obstante, aunque Dámaso Alonso sitúe La novela cervantina en el ámbito de ese primer conocimiento literario (el del lector), intentaremos demostrar en nuestro trabajo que también aquí (en uno de esos "escarceos mínimos" a los que se refería Jauralde ${ }^{31}$ ) pueden encontrarse sin duda también elementos que pertenecen al segundo escalón (crítica literaria) en incluso al tercer escalón (el de la Ciencia

${ }^{26}$ Grilli, G., Literatura caballeresca y re-escrituras cervantinas, Alcalá de Henares, Centro de Estudios Cervantinos, pp. 98-99.

27 Rey, A., y Sevilla, F., "Notas" a Don Quijote de la Mancha, Alcalá de Henares, Centro de Estudios Cervantinos, p. 35.

28 Alonso, D., "El hidalgo Camilote y el hidalgo don Quijote", p. 27.

29 Alonso, D., Poesía española, pp. 205-207.

${ }^{30}$ Portolés, J., Medio siglo de Filología Española (1896-1952): Positivismo e Idealismo, Madrid, Cátedra, p. 181.

31 Jauralde, P., op. cit., p. 5. 
de la Literatura). Cabe seńalar que la primera versión de La novela cervantina ve la luz en 1950, es decir, algunos años antes de la publicación de Poesía española (cuya primera edición data de 1957). La reflexión de Alonso sobre los modos de acercarse a la materia literaria no ha encontrado todavía su formulación definitiva, por lo que resulta lógico que su autor no ubique con exactitud su trabajo dentro de sus propias coordenadas teóricas.

Como decíamos, tres son los objetivos que se proponen al inicio de La novela cervantina: hablar de realismo, de literatura española y, por último, de Cervantes, con esa "normalidad crítica" a la que Dámaso Alonso apela ${ }^{32}$. El opúsculo se centra en realidad en establecer una serie de relaciones entre los dos primeros puntos y el tercero. Como ha indicado recientemente Rodríguez Mansilla en un artículo ya citado, la lectura del Quijote hecha por Alonso parte de la clásica idea de Menéndez Pidal, según la cual el hecho diferenciador de la literatura espańola respecto al resto de literaturas europeas es el carácter realista de la primera:

La novela cervantina es la suma de una serie de trabajos previos de Dámaso en torno a un tema que los discípulos de Menéndez Pidal, agrupados en el Centro de Estudios Históricos, heredaron de su maestro: el realismo como rasgo esencial de la literatura española. ${ }^{33}$

El propio Dámaso Alonso explica que su trabajo es también un diálogo con aquellos que le han antecedido:

Son, por otra parte, las reacciones de un hombre que ha dedicado parte de su vida a considerar estos temas; que ha querido contrastar, para ver si eran legítimas o no, opiniones que nos legaron nuestros mayores, sobre eso que se ha llamado el realismo español. ${ }^{34}$

Pero aquí Alonso no se está planteando esta problemática, precisamente porque ya la había estudiado anteriormente. Le basta con resumir las conclusiones extraídas de sus trabajos, conclusiones que se adhieren perfectamente a las tesis de Menéndez Pidal:

No queramos hacer piruetas; el realismo espańol existe, pero es necesario un adjetivo caracterizador; es un realismo psicológico. Desde el Poema del Cid (frente a la Canción de Roldán) y a través del Arcipreste de Hita, del Arcipreste de Talavera, de La Celestina y de El Lazarillo de Tormes, la literatura espańola con una constancia y en una gradación que se diría dirigida dentro de un plan supremo, se ha propuesto la pintura del alma humana. ${ }^{35}$

\footnotetext{
2 Alonso, D., La novela cervantina, en Obras completas, vol. 8, Madrid, Gredos, p. 587.

33 Rodríguez Mansilla, F., op. cit., p. 176.

34 Alonso, D., La novela cervantina, p. 588.

35 Ídem, p. 588.
} 
Como vemos, Dámaso Alonso parte de una idea, común por otra parte a lo largo del siglo XX, de que la literatura progresa. Ya en Enlace del realismo encontramos un apartado titulado "A la busca de la novela moderna. Tanteos españoles en el siglo XVI" ${ }^{36}$, donde se estudia la evolución de nuestra narrativa como la búsqueda de un nuevo molde que fuera capaz de sustituir a la épica y cuyo nacimiento definitivo hemos de situar en el Quijote. Es esta una visión habitual también hoy, que implica un concepto de progreso no demostrado (y posiblemente no demostrable) que impregna los estudios literarios, no solo en cuanto al realismo o al nacimiento de la novela, sino también, por ejemplo, en cuanto al surgimiento de nuestro teatro clásico. A propósito de esta idea, Rodríguez Mansilla comenta que:

Dámaso parte de esta visión providencialista, a partir de la cual Cervantes es la expresión máxima de algo más grande, la literatura espańola, que se mantiene uniforme en tema, técnica y propósitos desde su inicio con el Poema de Mío Cid. ${ }^{37}$

No obstante, hemos de entender adecuadamente las palabras de Dámaso Alonso. En rigor, como filólogo, no expone una visión providencialista. Sus palabras exactas son: "se diría dirigida dentro de un plan supremo". En esta expresión se plasma la admiración y perplejidad por la evolución de nuestra literatura. Se apunta, sí, un progreso artístico continuado, pero como descubrimiento, no como presupuesto. Esta diferencia resulta importante sobre todo si creemos posible considerar que "La novela cervantina es un texto que refuta, aunque sin referirlo explícitamente, a Mimesis de Erich Auerbach" ${ }^{38}$, porque en Mimesis se sostiene -y esta es probablemente su tesis principal- que la representación de la realidad en la literatura occidental es cada vez más perfecta, siguiendo una línea ascendente que culmina en el realismo decimonónico. Para Rodríguez Mansilla, el texto de Dámaso Alonso se opone dialécticamente al texto de Auerbach, en un debate similar al mantenido por Ernst R. Curtius y Menéndez Pidal acerca de la épica. El propio Alonso, como hemos visto, no deja pasar la oportunidad de citar las diferencias entre el Poema de mio Cid y la Chanson de Roland ${ }^{39}$, siguiendo la tesis de su maestro. Tanto Menéndez Pidal como su discípulo plantean la singularidad de la literatura espańola frente al resto de literatura europea, singularidad basada en el realismo como rasgo principal. En la búsqueda del realismo en la literatura espańola, Dámaso Alonso resalta dos "cimas" ${ }^{40}$, utilizando una metáfora que incide en la idea de "gradual ascensión" ${ }^{41}$ :

\footnotetext{
36 Alonso, D., Enlace del realismo, pp. 483-486.

${ }^{37}$ Rodríguez Mansilla, F., op. cit., p. 180.

${ }^{38}$ Ibid., p. 176.

39 Alonso, D., La novela cervantina, p. 588.

40 Ídem.

${ }^{41}$ Ídem.
} 
Hay en esta serie como una gradual ascensión, como una tradición técnica en esta pintura de los procesos que se desarrollan en el alma humana, hasta llegar a dos cimas: La Celestina, en donde por primera vez la técnica del realismo psicológico ha plasmado grandes, intensos caracteres; y El Lazarillo de Tormes, porque en él, también por primera vez, esa maestría de raíz medieval ha ido a insertarse en una verdadera novela. ${ }^{42}$

Desde este punto de vista, existe un desarrollo del realismo de las almas cada vez mayor, en una ascensión cronológica que llega hasta el Quijote (solamente hasta este, no más allá), de tal forma que las obras citadas por Dámaso Alonso desde el Cid constituyen algo así como formulaciones imperfectas de ese realismo. Esta concepción de la historia de la literatura supone un problema, pues en cierto modo intenta entender los textos más antiguos con el molde de textos más recientes y más canónicos. No se valoran las obras por sí mismas, sino como tentativas no logradas de obras posteriores. De este modo es visto también el resto de la obra de Cervantes frente al Quijote:

[Cervantes] acoge en su obra todas las formas novelescas que la modalidad española del Renacimiento, acoge en su obra todas las formas novelescas que la modalidad española del Renacimiento había creado. Las acoge a lo largo de su obra ensayándolas una a una en la $G a-$ latea, en las Novelas Ejemplares y en el Persiles [...]. ¡Cervantes, movido por la penuria y por la fama, siente la misma desazón que todo el siglo XVI había sentido buscando con afán la fórmula de la nueva novela! Y así como el siglo XVI ve premiado su esfuerzo al hallar con el Lazarillo la novela realista, lo que ha de ser fundamentalmente la novela moderna, Cervantes -cuando por fin definitivamente acierta- combina en el Don Quijote esa técnica fundamentalmente realista con todos los otros tipos de novela que el siglo XVI había ensayado. ${ }^{43}$

La idea de que la búsqueda del realismo recorre la literatura española hasta llegar al Quijote conlleva suponer una vinculación entre los diferentes textos únicamente por el hecho de pertenecer a la misma nación de origen. Sin embargo, en su argumentación, Dámaso Alonso, pese a citar en principio textos medievales que conoce bien (el Poema de mio Cid, el Corbacho y el Libro del Buen Amor), recurre especialmente a la Celestina y al Lazarillo como antecedentes del Quijote, y lo hace no solamente por ser "cimas" importantes en el proceso, sino también porque son obras que Cervantes conocía bien y que sin duda admiraba. Por tanto, la conexión entre la Celestina y el Lazarillo y el Quijote va más allá de la pertenencia a un mismo sustrato cultural (lo que Rodríguez Mansilla atribuye al uso del concepto de intrahistoria ${ }^{44}$ ) y se sitúa en el terreno de las fuentes literarias, que tan bien conocía el crítico. En este sentido, resulta relevante que en el tomo VIII de sus Obras com-

\footnotetext{
42 Ídem.

43 Ibid., p. 590-591.

44 Rodríguez Mansilla, F., op. cit., p. 177.
} 
pletas de Dámaso Alonso, editadas bajo la supervisión del propio estudioso, el texto de la Novela cervantina se sitúe justo después de los siguientes trabajos: Enlace del realismo, "Tirant lo Blanc", "La Celestina" y Tradición folklórica y creación artística en "El Lazarillo de Tormes". Es decir, en primer lugar se coloca un texto general sobre el realismo español, y posteriormente se sitúan tres trabajos sobre obras que, además de ser para Alonso fundamentales en la creación de ese realismo español, son también referencias indiscutibles en la narrativa cervantina. El propio estudioso lo señala, especialmente en su texto acerca del Tirant:

Es innegable que Cervantes aprendió en el libro de Martorell una buena lección. Se suelen señalar algunos puntos concretos del Quijote que parecen dejar traslucir huella del Tirant. Sin negarlos (ni mucho menos), me parece mucho más decisiva la lección general: de hombre a hombre, de novelista a novelista, de técnica a técnica. ${ }^{45}$

Al situar sus estudios sobre el Tirant, la Celestina y el Lazarillo como antesala de la novela cervantina, lo que en un principio es una visión de conjunto sobre la literatura española y su esencia fundamental, indirectamente toma un cariz de protoestudio sobre fuentes y materiales de la narrativa cervantina, así como del concepto de literatura presente en el Quijote. En este sentido, no es de extrańar que, al establecer las semejanzas y diferencias entre el Tirant y el Quijote en cuanto al espíritu literario de ambas obras, Alonso nos dé una de sus claves fundamentales sobre su lectura de la novela de Cervantes:

El Tirant y Don Quijote son libros que están como partidos por la mitad entre el idealismo caballeresco y positivismo diario. Esta coincidencia me parece el vestigio fundamental de que la obra de Martorell se encuentra en la de Cervantes. Evítese, sin embargo, la exageración. Porque ambas mitades están en conflicto o lucha en el Quijote; pero conviven sin desarmonía o contradicción en el Tirant. ${ }^{46}$

$\mathrm{Al}$ inicio de La novela cervantina, Dámaso Alonso insiste en que la búsqueda del realismo es el elemento constituyente fundamental de nuestra literatura. Sin embargo, hemos de tener en cuenta que sus trabajos sobre Cervantes se insertan en el camino abierto por el propio estudioso en "Escila y Caribdis de la literatura española". Este texto, publicado por primera vez en el año 1933, es el resultado de una conferencia que Alonso dio en 1927 con motivo del tricentenario de Góngora y que llevaba por título "Altura poética de la literatura espańola". Su artículo, según las palabras del propio autor, "traía una noción general nueva sobre la literatura española" ${ }^{47}$. Si "Me-

\footnotetext{
45 Alonso, D., "Tirant lo Blanc", p. 525-526.

46 Ibid, p. 526.

47 Soler Serrano, J., op. cit., min. 49:25-49:28.
} 
néndez Pidal adelanta el realismo literario [...], convirtiéndolo en rasgo primordial de nuestra epopeya y de toda la literatura espańola" ${ }^{48}$, Dámaso Alonso propone en cambio que tan importante resulta la vertiente idealista como la realista. Esta idea teórica soporta no solo sus trabajos sobre la poesía espańola, sino también, como decíamos, sus estudios cervantinos. Así lo demuestran las palabras finales de La novela cervantina:

De un lado el caballero y el ideal; de otro, la realidad. Y al estrellarse contra la realidad, se rompen a la par el último gran poema antiguo y la primera y máxima novela universal. Producto de un choque en el que los dos mundos que chocan se han fundido. Muerte y nacimiento a la vez. Glorioso nacimiento, pero triste. Y esto explica que ese libro que es todo un tesoro de cambiante humor, que ha hecho contorsionarse en carcajadas a millones y millones de rostros humanos, sea de verdad profundamente triste. A muchos nos hace llorar. ${ }^{49}$

Según Dámaso Alonso, Cervantes enfrenta el mundo del realismo y el del idealismo (representados en la novela por la realidad y la ficción caballeresca), y en el inestable punto de contacto entre ambos se crea una nueva literatura. Su punto de vista tiende de nuevo hacia lo general. En primer lugar, estas últimas palabras con las que cierra su trabajo suponen indirectamente un punto de acuerdo entre dos posturas críticas que sostendrán una agria polémica a lo largo del siglo XX. Como explica Montero Reguera ${ }^{50}$, en "El concepto de verdad en el Quijote" (publicado en 1948, algunos años antes que La novela cervantina) Alexander A. Parker alertaba de que a partir del siglo XIX se había producido en la lectura del Quijote un alejamiento del sentido literal a favor de una interpretación simbólica. Décadas después, Peter E. Russell proponía entender la novela de Cervantes fundamentalmente como un libro cómico 51. Por último, en The Romantic Approach to "Don Quixote" (1978), Anthony Close mostraba no solo su convencimiento de que en los siglos XVII y XVIII el Quijote fue entendido como un libro cómico, sino también de que esta era la única intención del propio Cervantes al crear su obra. De esta forma, se fue creando en el ámbito anglosajón una corriente que se oponía a la interpretación romántica de la novela. A este respecto, en su trabajo, Alonso es capaz de aunar ambas lecturas del Quijote, no solamente desde la perspectiva de la recepción de la obra, sino también desde el punto de vista de la intención autorial. Así, en Poesía española el crítico sostiene que "Don Quijote salió como su autor no lo esperaba; pero los primero capítulos tienen este mismo desamorado y truhanesco tono de cruda parodia" ${ }^{2}$.

\footnotetext{
${ }^{48}$ Portolés, J., op. cit., p. 81.

49 Alonso, D., La novela cervantina, p. 617.

${ }^{50}$ Montero Reguera, J., El "Quijote" y la critica contemporánea, Alcalá de Henares, Centro de Estudios Cervantinos, pp. 106-109.

51 Russell, P.E., “Don Quixote as Funny Book”, en Modern Language Review, núm. LXIV, pp. 312-326.

52 Alonso, Poesía española, p. 542.
} 
En segundo lugar, Dámaso Alonso proyecta su estudio sobre algunos aspectos del Quijote no solo hacia el sentido último del libro, sino, como advierte en la introducción, hacia la literatura española en general. Y, como decíamos, por más que insista en hablar de realismo español (con especial mención a los apartados titulados "Realismo de almas" y "Realismo de cosas"), para él el sentido último de la novela se encuentra, como en el resto de nuestra literatura, entre Escila y Caribdis. Si el Quijote aparece sobre todo como un libro que oscila entre dos polos, la concreción de esta naturaleza literaria se produciría en el personaje de Sancho Panza. En el apartado "Oscilación del carácter de Sancho", Dámaso Alonso matiza la concepción romántica, que identifica al personaje con el realismo y lo opone al idealismo quijotesco, pero también la postura de aquellos -cita a Unamuno y a Giovanni Papini- que sostienen la semejanza entre Sancho y su señor:

Durante mucho tiempo se ha pensado que de los dos planos, realista e idealista, que con genial confluencia forman la obra inmortal, Sancho era el neto representante del primero. Pero en nuestros días Unamuno y Papini han defendido la tesis de que sobre Sancho se vierte la idealidad del Caballero, que penetra así en el mundo de lo fantasmagórico, que es, a su manera, otro Quijote. ${ }^{53}$

Como Papini y Unamuno (y también como Salvador de Madariaga ${ }^{54}$, a quien nuestro autor no cita), Alonso está de acuerdo en que al principio Sancho "entra plenamente en el mundo de las aventuras" 55 , pero habla de un proceso de "engaño y desengaño" 56 como en el capítulo del hidalgo del Lazarillo, porque tras el bálsamo de fierabrás, el escudero "no cree ya en los encantamientos de su amo" ${ }^{57}$, lo que lleva a utilizar la locura de don Quijote para engañarle:

Sancho, en este instante, no sólo está fuera del mundo irreal, sino que cae dentro de la órbita picaresca, como Lázaro tras el coscorrón, como Guzmán tras los huevos con pollo y la carne mortecina. ${ }^{58}$

Pero es precisamente este ejemplo - de nuevo usa un texto fundamental de nuestra literatura que a la vez es una importante fuente cervantina-, el que le sirve para contraponer el personaje de Lázaro al de Sancho:

\footnotetext{
53 Alonso, La novela cervantina, p. 595.

54 Madariaga, S., Guia del lector del "Quijote, Madrid, Espasa-Calpe.

55 Alonso, D., La novela cervantina, p. 598.

56 Ibid., p. 599.

57 Ibid., p. 599.

58 Ibid., p. 599.
} 
Pero Sancho ha de titubear entre picaresca e idealidad a lo largo de todo el libro. Porque lo característico del alma de Sancho es que en ella el movimiento de ilusión y desilusión se reproduce, ondulatoriamente, a través de todas las páginas de la obra. ${ }^{59}$

Y, dialogando con los autores que habían reflexionado anteriormente sobre el personaje, concluye:

La fórmula de Unamuno y Papini es demasiado sencilla: Sancho no pertenece ni al mundo de lo real (sería un pícaro), ni al de lo fantasmagórico (sería un caballero). Lo que le define es estar oscilando, pasando constantemente de un plano al otro, de la ilusión a la realidad desilusionada. ${ }^{60}$

Publicado de forma autónoma, el estudio de Dámaso Alonso sobre el carácter del escudero llevaba el título de "Sancho-Quijote; Quijote-Sancho". Se remarcaba así el estudio de Sancho Panza en comparación con el de don Quijote, tal y como había hecho la crítica precedente. En La novela cervantina, en cambio, al titular el apartado como "Oscilación del carácter de Sancho", se resalta la función del escudero como enganche entre los dos mundos que chocan en el Quijote: el idealismo y el realismo, que condensan el carácter fundamental de la literatura española según Alonso. Por ello, al final de su análisis, vuelve a establecer relaciones con las obras maestras de nuestra literatura: "en Cervantes, como en sus predecesores, el Poema del Cid, el Arcipreste de Hita, el Arcipreste de Talavera, la Celestina y e Lazarillo, las almas se desnudan hablando" ${ }^{61}$. En la versión original de su trabajo (concebido, como hemos dicho, como artículo independiente), estas relaciones se establecen no solo al final, sino también al comienzo, en un párrafo inicial que desaparece en La novela cervantina:

En literatura espańola, la pintura de los procesos de engaño tiene una larga antigüedad (Cantar de Mio Cid, Arcipreste de Hita, Celestina). ¿Se ha estudiado alguna vez el largo y complicado proceso de engaño y desengaño que nos ofrece nuestro amigo Sancho Panza? ${ }^{62}$

Creemos haber demostrado que, pese a que Dámaso Alonso presente La novela cervantina como "sus reacciones personales" ${ }^{3}$ frente a Cervantes, su estudio tiene también un gran componente de estudio crítico, de ese "segundo conocimiento literario" al que el crítico se refiere en Poesía española. Ahora bien, ¿es posible encontrar

\footnotetext{
59 Ibid., p. 599.

60 Ibid., p. 602.

61 Ibid., p. 603

62 Alonso, "Sancho-Quijote, Sancho-Sancho", en Del Siglo de Oro a este siglo de siglas, Madrid, Gredos, p. 9.

${ }^{63}$ Alonso, D., La novela cervantina, p. 587.
} 
también algunos indicios de ese tercer conocimiento literario que Alonso denomina Estilística o Ciencia de la Literatura? Como veíamos al comienzo de nuestro trabajo, a priori parece complicado que desde la Estilística se pretendiera hacer un estudio global del Quijote, tal como apuntaba Jauralde ${ }^{64}$. No obstante, por la naturaleza de nuestro trabajo, nos referimos aquí no tanto a la Estilística como método de estudio de los textos que predominó en la Escuela Filológica Española, sino a la propuesta (casi anhelo) de un estudio científico de la literatura, en la concepción original que Dámaso Alonso expone en Poesía española. En este estudio, Estilística se define como "la ciencia del estilo" ${ }^{65}$. Por su parte, el estilo es "lo peculiar, lo diferencial de un habla" ${ }^{66}$. Así pues la estilística sería la ciencia del habla en dos aspectos, del habla corriente (estilística lingüística) y del habla literaria (estilística literaria o ciencia de la literatura ${ }^{67}$. En principio, en La novela cervantina, así como en los escasos textos cervantinos que Dámaso Alonso dejó fuera del compendio, no encontramos un estudio del habla, como sí encontramos en otros estudios cervantinos de filólogos muy cercanos a nuestro autor ${ }^{68}$. No obstante, Alonso advierte que "este estudio del habla como creación individual abarcará toda la complejidad creativa del habla misma" ${ }^{99}$. En este sentido resultan importantes las siguientes puntualizaciones:

Estilo es todo lo que individualiza a un ente literario: a una obra, a un escritor, a una época, a una literatura. El estilo es el único objeto de la crítica literaria. y la misión verdadera de la historia de la literatura — esa lamentable necrópolis de nombres y de fechas- consiste en diferenciar, valorar, concatenar y seriar los estilos particulares. ${ }^{70}$

Desde esta perspectiva es perfectamente comprensible la insistencia de Dámaso Alonso en proyectar todas sus indagaciones cervantinas al ámbito de la historia de nuestra literatura. Bajo la apariencia de "sus reacciones personales", es decir, bajo la apariencia de un texto que pertenece al primer escalón del conocimiento literario, el del mero "lector", encontramos preocupaciones que pertenecen no solo al segundo escalón (conocimiento crítico) sino también a ese tercer escalón, a ese anhelo de conocimiento científico que para Dámaso Alonso es la Estilística. Su análisis del Quijote y de Cervantes en las coordenadas de una literatura nacional tiene, por tanto, unos moldes muy parecidos a los que aplicaba en su análisis de la poesía.

\footnotetext{
${ }^{64}$ Jauralde, P., op. cit.

65 Alonso, Poesía española, p. 401.

66 Ibid., p. 401.

${ }^{67}$ Ibid., p. 401. A diferencia de lo que sucede en la mayoría de Poesía española, en este pasaje Dámaso Alonso deja en minúscula los términos "estilística" y "ciencia de la literatura"; respetamos el uso del autor.

${ }_{68}$ Nos referimos, por ejemplo, a textos como "Las prevaricaciones idiomáticas de Sancho", de Amado Alonso.

${ }^{69}$ Alonso, D., Poesía española, p. 401.

${ }^{70}$ Alonso, D., La poesía de san Juan de la Cruz (desde esta ladera), Madrid, Aguilar, p. 263.
} 


\section{Referencias Bibliográficas}

Alonso, Amado (1948), "Las prevaricaciones idiomáticas de Sancho", en Nueva Revista de Filología Hispánica, vol. II, pp. 1-20.

Alonso, Dámaso (1942), La poesía de san Juan de la Cruz (desde esta ladera), Madrid, Aguilar.

- (1968), "Sancho-Quijote, Sancho-Sancho", en Del Siglo de Oro a este siglo de siglas, Madrid, Gredos, pp. 9-19.

- (1968), "El hidalgo Camilote y el hidalgo Don Quijote", en Del Siglo de Oro a este siglo de siglas, Madrid, Gredos, pp. 20-28.

- (1976), Poesía española: ensayo de métodos y límites estilísticos, Madrid, Gredos.

- (1986), Obras completas, vol. 8, Madrid, Gredos.

- (1986), Enlace del realismo, en Obras completas, vol. 8, Madrid, Gredos, pp. 483-498.

- (1986), "Tirant lo blanc", novela moderna, en Obras completas, vol. 8, Madrid, Gredos, pp. 499-536.

- (1986), "La Celestina", en Obras completas, vol. 8, Madrid, Gredos, pp. 537 566.

- (1986), Tradición folklórica y creación artística en "El Lazarillo de Tormes", en Obras completas, vol. 8, Madrid, Gredos, pp. 567-586.

- (1986), La novela cervantina, en Obras completas, vol. 8, Madrid, Gredos, pp. 587-618.

Auerbach, Erich (1989), Mímesis: la representación de la realidad en la literatura occidental, Madrid, Fondo de Cultura Económica de España.

Castro, Américo (1957), Hacia Cervantes, Madrid, Taurus

- (1966), Cervantes y los casticismos españoles, Madrid-Barcelona, Alfaguara.

- (1980), El pensamiento de Cervantes, Barcelona, Noguer.

Close, Anthony (1978), The Romantic Approach to "Don Quixote". A Critical History of the Romantic Tradition in "Quixote" Criticism, Cambridge, Cambridge University Press.

Descouzis, Paul (1966), Cervantes, a nueva luz, Fráncfort, Vittorio Klostermann. 
Fernández, Jaime (2008), Bibliografía del "Quijote" por unidades narrativas y materiales de la novela, Alcalá de Henares, Centro de Estudios Cervantinos.

González de Amezúa, Agustín (1956), Cervantes creador de la novela corta española, Madrid, CSIC.

Grilli, Giuseppe (2004), Literatura caballeresca y re-escrituras cervantinas, Alcalá de Henares, Centro de Estudios Cervantinos.

Jauralde, Pablo (2005), "Cervantes y la escuela filológica española", en Voz y letra, vol. 16, pp. 3-14.

Madariaga, Salvador (2005), Guia del lector del "Quijote, Madrid, Espasa-Calpe.

Montero Reguera, José (1997), El “Quijote” y la crítica contemporánea, Alcalá de Henares, Centro de Estudios Cervantinos.

Montero Reguera, José (2005), El “Quijote” durante cuatro siglos: lecturas y lectores, Valladolid, Universidad de Valladolid.

Moreno BÁez, Enrique (1977), Reflexiones sobre el "Quijote", Madrid, Editorial Prensa Española.

Parker, Alexander (1948), "El concepto de verdad en el Quijote", en Revista de Filología Española, núm. 32, pp. 287-305.

Percas, Helena (1975), Cervantes y su concepto de arte: estudio crítico de algunos aspectos y episodios del "Quijote", Madrid, Gredos.

Portolés, José (1986), Medio siglo de Filología Española (1896-1952): Positivismo e Idealismo, Madrid, Cátedra.

Rey, Antonio y Sevilla, Florencio (1994), "Notas" a Don Quijote de la Mancha, Alcalá de Henares, Centro de Estudios Cervantinos.

Rodríguez Mansilla, Fernando (2007), “Dámaso Alonso lee el Quijote: nación, realismo e intrahistoria en el cervantismo español”, en eHumanista, vol. 9, pp. 175-195.

Russell, Peter E. (1969), “Don Quixote as Funny Book”, en Modern Language Review, núm. LXIV, pp. 312-326.

Soler Serrano, Joaquín (dir.) (2000), "Entrevista a Dámaso Alonso", en $A$ fondo, Radiotelevisión Española, Barcelona, Ediciones Trasbals Multimedia, disponible en http://www.youtube.com/watch?v=IUKF3RGuP_w, (28/3/2017).

DOI: http://dx.doi.org/10.15366/bp2018.18.018

Bajo Palabra. II Época. No18. Pgs: 355-372 